\title{
Syphilis intervention in pregnancy: Zambian demonstration project
}

\author{
Subhash K Hira, Ganapati J Bhat, Davy M Chikamata, Benjamin Nkowane, George Tembo, \\ Peter L Perine, Andre Meheus
}

\begin{abstract}
Despite availability of simpler serologic tests for syphilis and near cure with penicillin, unacceptably high prevalence of infectious maternal syphilis exist in many developing countries, including Zambia. It is the foremost risk factor for mid-trimester abortions, stillbirths, prematurity and morbidity and mortality among infants born with congenital syphilis in Zambia. An intervention project was conducted in Lusaka aimed at demonstrating the effectiveness of new health education methods and prenatal screening for syphilis in reducing the adverse outcomes during pregnancy. During pre-intervention phase, approximately 150 consecutive pregnant women from each of the three study and the three control centres were recruited when they presented in labour at the University Teaching Hospital. The intervention phase lasted for one year at the three study centres during which new methods of health education were introduced to improve early attendances during pregnancy. Also, on-site syphilis screening was performed twice during pregnancy and seroreactive women, and in many cases their sexual partners, were treated by the existing prenatal clinic staff. During the post-intervention phase the steps of pre-intervention phase were repeated to evaluate the impact of intervention. Overall, $8.0 \%$ of women were confirmed seroreactive for syphilis; there was no difference between the study and the control centres $(p>0.05)$. Fifty seven percent $(132 / 230)$ of syphilitic pregnancies ended with an adverse outcome, that is, abortion (RR 5.0), stillbirth (RR 3.6), prematurity (RR 2.6) and low birth weight $(R R \mathbf{7 \cdot 8 )}$. The overall risk of
\end{abstract}

University Teaching Hospital, Lusaka, Zambia

Subhash K Hira, Ganapati J Bhat, Davy M Chikamata, George Tembo

World Health Organisation, Geneva

Benjamin Nkowane, Andre Meheus

Uniformed Services, University of Health Sciences, Bethesda, Maryland, USA

Peter L Perine adverse outcomes due to syphilis was $8 \cdot 29(95 \%$ confidence interval $6 \cdot 53,10 \cdot 53)$. The new methods of health education were effective and the percentage of women who had their first prenatal visit under 16 weeks of gestation improved from $9 \cdot 4$ to $42 \cdot 5$. Although screening and treatment during intervention was suboptimal, the adverse outcomes attributable to syphilis were reduced to $28.3 \%$; this is almost a two-third reduction when compared with $72.4 \%$ of adverse outcomes at control centres $(p<0.001)$. The intervention is culturally and politically acceptable in Zambia. The cost of each prenatal screening is US\$0.60 and of averting each adverse outcome US\$12. In countries with high rates of syphilis, there is an urgent need for STD control and Maternal and Child Health (MCH) programmes to pool their resources together to revitalise the prenatal care.

\section{Introduction}

Venereal syphilis continues to be a serious public health problem in many countries. ${ }^{1}$ In several African nations high rates of maternal and congenital syphilis have been reported. ${ }^{2-6}$ In Zambia $12.8 \%$ pregnant women in urban as well as rural areas have reactive serologic tests for syphilis and one sixth of these infections are freshly acquired during pregnancy. ${ }^{7}$ As a result there is a high incidence of congenital syphilis ${ }^{8-10}$ as well as abortions and stillbirths $s^{5}$ attributed to this infection. A case-control study of stillbirths at the University Teaching Hospital in Lusaka, Zambia showed that rapid plasma reagin (RPR) titre of $>1: 32$ carried a relative risk of $21 .{ }^{11}$ These studies also indicate syphilis to be the foremost risk factor associated with $20-30 \%$ of perinatal mortality rate of 50/1000 total births.

Adverse pregnancy outcomes due to syphilis are preventable through routine serological screening and treatment early in pregnancy. This is well demonstrated by a very low incidence of congenital syphilis in industrialised countries. ${ }^{12}{ }^{13}$ Although $90-$ $92 \%$ of pregnant women attend prenatal services in $\mathrm{Zambia}^{7}$ and serological screening is mandatory, several barriers to its effective implementation have 
been recognised:(a) late attendances at prenatal clinics; (b) screening test for syphilis not performed in $70-80 \%$ of prenatal attenders; (c) failure to provide treatment to all seroreactive women and their sexual partner(s). It is established that only a quarter of seroreactive women receive treatment and the majority if not all their sexual partners remain untreated; and (d) failure to recognise infections acquired late in pregnancy, that is, after initial screening at first prenatal visit.

Hence, a demonstration project was designed to overcome the barriers and to demonstrate the effectiveness of prenatal syphilis screening in reducing the adverse pregnancy outcomes. This was later to become the basis for an improved national maternal syphilis control programme.

\section{Patients and methods}

A syphilis intervention project was developed targetted at prenatal attenders. The objectives were: (1) to develop and evaluate the effectiveness of new health education methods in eliciting attendance by 16 weeks of pregnancy in at least $75 \%$ of attenders; (2) to implement and evaluate prenatal syphilis screening in reducing adverse pregnancy outcomes by (a) performing serological screening test on all attenders at first visit and repeating it early in third trimester; (b) treating all reactive women and their sexual partners adequately with appropriate drug regimen; and (3) to demonstrate improvement in pregnancy outcomes in the population covered, a year after implementation of the intervention outlined above.

Three periurban health centres in Lusaka, each serving an average population of approximately 20,000 in shanty compounds were chosen as study centres. Another three comparable periurban health centres were chosen to provide control population. Criteria for choosing study and control centres were that these centres should be serving a population comparable in size and in socio-economic status.

A total of 12 staff members working at the prenatal clinics in the three study centres, six midwives at the labour ward at University Teaching Hospital (UTH), and three field supervisors were trained. Two 5-day workshops were conducted at UTH to train the staff in the methods of health education, clinical evaluation, serological tests for syphilis and assessment of pregnancy outcomes.

Pre-intervention phase: Between September 1985 and January 1986, the initial phase was conducted at UTH labour ward. It was targetted to recruit approximately 150 consecutive pregnant women from each of the three study centres. An equal number of women who had attended prenatal care at the three control centres and presented at the UTH for delivery were also consecutively recruited into the study. Detailed prenatal histories were obtained and physical examinations were performed. Serologic screening for syphilis was performed with rapid plasma reagin test (RPR) on serum samples of all the mothers and also on cord blood. A total of 491 women from the study centres and 434 women from the control centres were entered in the study.

Intervention phase: Between February 1986 and January 1987, active syphilis intervention was carried out by existing prenatal clinic staff at the three study centres. The components of intervention were:

(1) Health education/information aimed at motivating early attendances to prenatal clinics and improving health care seeking behaviours. Three target groups were identified at each study centre: (a) sexually active women attending prenatal, family planning, and under-five clinics; (b) sexually active men and women attending general out-patient clinics; (c) elderly men and women attending general out-patient clinics. The latter group was considered important since in a traditional society, this group tends to be influential in motivating behavioural change.

The health education/information messages were developed with the assistance of local leaders. Messages were kept simple, accurate, clear and repetitive. Use of local words, pictures and stories was encouraged. All communication material was pre-tested to find out if the target groups understood the idea, believed the messages, and thought it related to them.

Several educational methods were used at each centre. These included lectures (with or without flipcharts), question and answer sessions, brain storming, handouts, audio messages, group discussions and individual counselling (for those found seroreactive for syphilis). Each session was attended by $15-20$ persons. Each topic was delivered several times in the year (table 1) so as to give each client an opportunity to be exposed to a topic at least once. Messages were modified at 6 and 9 months to make them more simple and understandable.

Before starting intervention, a questionnaire was administered to approximately 150 prenatal attenders at each study centre to determine: (a) the pattern and frequency of prenatal attendance; and (b) the reasons for attending late in pregnancy. Towards the end of intervention, a similar questionnaire was administered to approximately 150 prenatal attenders at each study centre to determine the impact of health education/information on pattern and frequency of prenatal attendances.

(2) Syphilis screening and treatment programme: serological screening was performed by the prenatal clinic staff using a simple RPR card test. Reactive sera were confirmed with Fluorescent Treponemal Antibody-Absorption (FTA-Abs) test. Positive 
Table 1 List of topics covered for health education at study centres

\begin{tabular}{|c|c|c|c|c|}
\hline & & \multicolumn{3}{|c|}{ No of topics delivered/yr } \\
\hline & & Centre 1 & Centre 2 & Centre 3 \\
\hline $\begin{array}{l}1 . \\
2 . \\
3 . \\
4 . \\
5 . \\
6 . \\
7 . \\
8 . \\
9 . \\
10 . \\
11 . \\
12 . \\
13 . \\
14 . \\
15 . \\
16 . \\
17 . \\
18 . \\
19 . \\
20 .\end{array}$ & $\begin{array}{l}\text { Importance of prenatal care } \\
\text { Gonorrhoea } \\
\text { AIDS } \\
\text { Diarrhoeal diseases } \\
\text { Immunisation } \\
\text { Syphilis } \\
\text { Vaginal discharge } \\
\text { Anemia in pregnancy } \\
\text { Chancroid } \\
\text { Importance of nutrition } \\
\text { Congenital syphilis } \\
\text { STDs (General) } \\
\text { Home delivery } \\
\text { Methods \& importance of family planning } \\
\text { Jaundice } \\
\text { Worm infestation } \\
\text { Causes of abortion } \\
\text { Care of the new born } \\
\text { Measles } \\
\text { Others (<10 times) } \\
\text { Diet in pregnancy } \\
\text { Herpes genitalis } \\
\text { Scabies } \\
\text { Pubic lice } \\
\text { LGV } \\
\text { Venereal warts } \\
\text { What is pregnancy } \\
\text { Weaning } \\
\text { Importance of under-five clinics } \\
\text { Ante and postpartum haemorrhage } \\
\text { Malaria in pregnancy } \\
\text { Sore eyes in newborn } \\
\text { Breast feeding } \\
\text { Backyard gardening } \\
\text { Budgeting } \\
\text { Total }\end{array}$ & $\begin{array}{r}34 \\
26 \\
30 \\
36 \\
20 \\
29 \\
15 \\
21 \\
17 \\
26 \\
15 \\
18 \\
14 \\
34 \\
0 \\
10 \\
12 \\
12 \\
18 \\
70\end{array}$ & $\begin{array}{r}40 \\
38 \\
34 \\
30 \\
28 \\
26 \\
40 \\
22 \\
20 \\
20 \\
19 \\
18 \\
15 \\
26 \\
12 \\
12 \\
0 \\
10 \\
10 \\
65\end{array}$ & $\begin{array}{r}30 \\
31 \\
10 \\
34 \\
15 \\
42 \\
12 \\
15 \\
18 \\
40 \\
0 \\
13 \\
10 \\
50 \\
0 \\
10 \\
15 \\
10 \\
29 \\
101\end{array}$ \\
\hline
\end{tabular}

reactors were identified and treated with a single im dose of 2.4 million units of benzathine penicillin. Special messages were passed through the women to their sexual partners to attend the clinic for early treatment. A total of 5007 prenatal attenders at the three study centres entered in the programme. Simultaneously, the three control centres continued their "normal" prenatal and STD control activities which also included health education, prenatal syphilis screening and treatment of seroreactors and their sexual partners.

Post-intervention phase: At the end of one year of intervention, a study similar to that performed for the pre-intervention phase was repeated at the UTH labour ward. Between February and June 1987, a total of 806 women from three study centres and 1274 women from three control centres were consecutively recruited in the study.

Programme performance was evaluated by: (a) analysing the data on pregnancy outcomes in the initial and final phase studies involving the study population; and (b) comparing such data with those of the control population. Student's one tailed and two tailed tests and chi square were used as tests of significance to assess the difference.

\section{Results}

The mean age of women attending study and control centres for the purpose of prenatal care was 24.5 years $(S D=5 \cdot 8)$. Single women were younger with mean age of 19.5 years $(S D=3 \cdot 8)$. Also, $86.5 \%$ of all prenatal attenders were married, $12.4 \%$ were working, and $58.7 \%$ had attained some level of primary education (table 2 ).

Overall, $8.0 \%$ of women were seroreactive for syphilis. There was no significant difference in seroprevalence between the study and the control centres (table 2). Except for its correlation with lifetime number of sexual partners, syphilis seroprevalence was independent of marital status and level of education. The latter finding suggests widespread syphilitic infection in the community.

Prior to intervention, 68/723 (9.4\%) of women at the study centres had their first prenatal visit before 16 weeks of gestation. However, subsequent to health education during the year of intervention, the pattern of attendance at the prenatal clinics changed and 194/ $457(42.5 \%)$ of attenders had their first prenatal visit under 16 weeks of gestation (table 3 ). The reasons for delayed first prenatal visits were variable (table 4).

The syphilis screening and treatment of sero- 
Table 2 Demographic features of pregnant women in Lusaka, Zambia

\begin{tabular}{|c|c|c|c|c|c|c|}
\hline \multirow[b]{2}{*}{ Demographic factors } & \multicolumn{2}{|c|}{ Pre-intervention } & \multicolumn{2}{|c|}{ Post-intervention } & \multirow[b]{2}{*}{$\begin{array}{l}\text { Mean } \\
\text { total }\end{array}$} & \multirow[b]{2}{*}{ Significance } \\
\hline & $\begin{array}{l}\text { Study } \\
\text { centres } \\
(n=491)\end{array}$ & $\begin{array}{l}\text { Control } \\
\text { centres } \\
(n=434)\end{array}$ & $\begin{array}{l}\text { Study } \\
\text { centres } \\
(n=806)\end{array}$ & $\begin{array}{l}\text { Control } \\
\text { centres } \\
(n=1274)\end{array}$ & & \\
\hline $\begin{array}{l}\text { 1. Mean Age (yr) } \\
\text { 2. Mean parity } \\
\text { 3. Mean house-keeping income } \\
\text { (Kwacha) per month }\end{array}$ & $\begin{array}{r}24 \cdot 39 \\
2 \cdot 40 \\
141 \cdot 47\end{array}$ & $\begin{array}{r}24 \cdot 15 \\
2 \cdot 35 \\
140 \cdot 30\end{array}$ & $\begin{array}{r}24 \cdot 55 \\
2 \cdot 60 \\
232 \cdot 41\end{array}$ & $\begin{array}{r}24 \cdot 60 \\
2 \cdot 32 \\
255 \cdot 70\end{array}$ & $\begin{array}{r}24 \cdot 49 \\
2 \cdot 41 \\
212 \cdot 72\end{array}$ & $\begin{array}{l}\text { NS } \\
\text { NS } \\
\text { NS }\end{array}$ \\
\hline $\begin{array}{l}\text { 4. Mean gravida } \\
\text { 5. Mean life-time sexual partners } \\
\text { 6. Marital status }\end{array}$ & $\begin{array}{l}3 \cdot 42 \\
2 \cdot 29\end{array}$ & $\begin{array}{l}3 \cdot 60 \\
2 \cdot 11\end{array}$ & $\begin{array}{l}3.59 \\
2.07\end{array}$ & $\begin{array}{l}3 \cdot 59 \\
2 \cdot 19\end{array}$ & $\begin{array}{l}3 \cdot 56 \\
2 \cdot 16\end{array}$ & $\begin{array}{l}\text { NS } \\
\text { NS } \\
\text { NS }\end{array}$ \\
\hline $\begin{array}{l}\text { never married } \\
\text { married } \\
\text { divorced } \\
\text { widowed } \\
\text { remarried }\end{array}$ & $\begin{array}{r}9 \cdot 4 \\
89 \cdot 6 \\
0.6 \\
0.4 \\
0.0\end{array}$ & $\begin{array}{r}7 \cdot 4 \\
91 \cdot 7 \\
0 \cdot 5 \\
0 \cdot 2 \\
0 \cdot 2\end{array}$ & $\begin{array}{r}12 \cdot 3 \\
84 \cdot 1 \\
1 \cdot 0 \\
0 \cdot 2 \\
2 \cdot 4\end{array}$ & $\begin{array}{r}10 \cdot 9 \\
85 \cdot 2 \\
1 \cdot 2 \\
0 \cdot 2 \\
2 \cdot 5\end{array}$ & $\begin{array}{r}10 \cdot 6 \\
86 \cdot 5 \\
0 \cdot 9 \\
0 \cdot 2 \\
1 \cdot 7\end{array}$ & \\
\hline $\begin{array}{l}\text { 7. Occupation } \\
\text { working } \\
\text { nonworking }\end{array}$ & $\begin{array}{r}9 \cdot 2 \\
90 \cdot 8\end{array}$ & $\begin{array}{l}10 \cdot 4 \\
89 \cdot 5\end{array}$ & $\begin{array}{l}12 \cdot 9 \\
87 \cdot 3\end{array}$ & $\begin{array}{l}13.9 \\
86.1\end{array}$ & $\begin{array}{l}12 \cdot 4 \\
87 \cdot 6\end{array}$ & NS \\
\hline $\begin{array}{l}\text { 8. Education } \\
\text { none } \\
\text { primary } \\
\text { secondary } \\
\text { higher } \\
\text { 9. RPR reactivity (maternal) }\end{array}$ & $\begin{array}{r}10 \cdot 8 \\
62 \cdot 4 \\
26 \cdot 0 \\
0 \cdot 8 \\
8 \cdot 7\end{array}$ & $\begin{array}{r}15 \cdot 0 \\
60 \cdot 4 \\
24 \cdot 2 \\
0 \cdot 5 \\
6 \cdot 7\end{array}$ & $\begin{array}{r}8 \cdot 7 \\
59 \cdot 8 \\
30 \cdot 0 \\
1 \cdot 5 \\
7 \cdot 7\end{array}$ & $\begin{array}{r}10 \cdot 3 \\
56 \cdot 1 \\
31 \cdot 6 \\
2 \cdot 0 \\
8 \cdot 3\end{array}$ & $\begin{array}{r}10 \cdot 6 \\
58 \cdot 7 \\
29 \cdot 2 \\
1 \cdot 4 \\
8 \cdot 0\end{array}$ & NS \\
\hline
\end{tabular}

reactors during intervention was sub-optimal. Four hundred and seventy-three of $806(58.6 \%)$ of attenders at the study centres and 182/1274 (14.3\%) of attenders at the control centres had had syphilis test performed at first visit. By comparison, third trimester screening was performed on $15.1 \%$ and $1 \cdot 6^{\circ}{ }_{0}$ at the study and the control centres, respectively. Of 74 women tested seroreactive at study centres, $34(45.9 \%)$ were treated; 29 of them brought their spouses for treatment. By comparison, $9 / 36$ $\left(25.0^{\circ} \%\right)$ of seroreactors at control centres were treated; three of them brought their spouses for treatment.

Almost $58 \%$ of syphilitic pregnancies had some adverse outcome, namely abortion $(14 \cdot 8 \%)$, stillbirth $\left(7 \cdot 0^{\circ} \mathrm{o}\right)$, preterm/premature $(12.2 \%)$, low birth weight $(21.3 \%)$ and congenital syphilis $(2 \cdot 2 \%)$. By comparison, $10 \%$ of nonsyphilitic pregnancies also had adverse outcomes (table 5). However, subsequent to the intervention, the adverse outcomes among syphilitic pregnancies at the study centres was reduced to $28.3 \%$; almost a two-third reduction when compared with those at the control centres (table 6). The adverse outcomes among nonsyphilitic

Table 3 Pattern of prenatal attendance at the study centres (pre-and post-intervention)

\begin{tabular}{lcc}
\hline Weeks gestation & $\begin{array}{l}\text { Pre-intervention } \\
n=723(\%)\end{array}$ & $\begin{array}{l}\text { Post-intervention } \\
n=457(\%)\end{array}$ \\
\hline$<12$ & $8(1 \cdot 1)$ & $67(14 \cdot 7)$ \\
$12-16$ & $60(8 \cdot 3)$ & $127(27 \cdot 8)$ \\
$17-20$ & $128(17 \cdot 7)$ & $148(32 \cdot 4)$ \\
$21-24$ & $239(33 \cdot 1)$ & $88(19 \cdot 3)$ \\
$25-28$ & $226(31 \cdot 3)$ & $21(4 \cdot 6)$ \\
$29-32$ & $40(5 \cdot 5)$ & 4 \\
$33-36$ & $22(3 \cdot 0)$ & 2 \\
\hline
\end{tabular}

pregnancies at the study centres also showed a significant decline to $8.1 \%$ as compared with $11.1 \%$ at the control centres $(p<0.05)$, possibly due to broad-based health education programme undertaken during the intervention.

Considering FTA-Abs as confirmatory test, the sensitivity of RPR card test was 138/175 (78.9\%) and the specificity was $385 / 427(90 \cdot 2 \%)$.

\section{Discussion}

This demonstration project confirmed that health education is possible in the existent set-up at the health centres. The effectiveness of new health education efforts was evident by the change observed in the pattern of attendance at the study centres. There was improvement in first prenatal visits before 16 weeks of pregnancy from $9 \cdot 4 \%$ to $42.5 \%$. However, this did not meet the study expectation of at least $75 \%$ of the prenatal clinic attenders presenting for their first visit before 16 weeks of pregnancy. In fact, at the end of intervention more than half of the late attendees still believed that it was not necessary to attend prenatal clinic early in preg-

Table 4 Reasons for late attendance (respondents $n=263$ )

\begin{tabular}{lc}
\hline & Number $(\%)$ \\
\hline Thought not necessary & $145(55 \cdot 1)$ \\
Did not want to declare pregnancy early & $23(8 \cdot 7)$ \\
$\quad$ owing to traditional customs & 8 \\
Early declaration of pregnancy might & \\
$\quad$ adversely affect the baby & 0 \\
Domestic problems & $28(10 \cdot 6)$ \\
Transport problems & $59(22 \cdot 4)$ \\
Unwell &
\end{tabular}


Table 5 Adverse pregnancy outcomes among seroreactive and nonreactive women

\begin{tabular}{lccc}
\hline & \multicolumn{2}{l}{ Syphilis (RPR E FTA-Abs) } & \\
\cline { 2 - 4 } & $\begin{array}{lll}\text { Reactive } \\
n=230\end{array}$ & $\begin{array}{l}\text { Nonreactive } \\
n=2647\end{array}$ & $\begin{array}{l}\text { Relative risk } \\
(95 \% \text { CI) }\end{array}$ \\
\hline Abortion & $34(14 \cdot 8)$ & $62(2 \cdot 3)$ & $5 \cdot 03(3 \cdot 72.6 \cdot 80)$ \\
Stillbirth & $16(7 \cdot 0)$ & $43(1 \cdot 6)$ & $3 \cdot 57(2 \cdot 31,5 \cdot 53)$ \\
Preterm/premature & $28(12 \cdot 2)$ & $117(4 \cdot 4)$ & $2 \cdot 61(1 \cdot 83,3 \cdot 74)$ \\
Low birth weight & $49(21 \cdot 3)$ & $48(1 \cdot 8)$ & $-76(6 \cdot 09,9 \cdot 88)$ \\
Congenital syphilis & $5(2 \cdot 2)$ & - & $8 \cdot 29(6.53,10 \cdot 53)$ \\
Total & $132(57 \cdot 4)$ & $270(10 \cdot 2)$ & \\
\hline
\end{tabular}

Table 6 Adverse pregnancy outcomes among seroreactive women before and after intervention

\begin{tabular}{|c|c|c|c|c|c|}
\hline \multirow[b]{3}{*}{ Complications } & \multicolumn{4}{|c|}{ Syphilis reactive $(n=230)$} & \multirow[b]{3}{*}{ Total } \\
\hline & \multicolumn{2}{|c|}{ Pre-intervention } & \multicolumn{2}{|c|}{ Post-intervention } & \\
\hline & $\begin{array}{l}\text { Study centres } \\
n=41\end{array}$ & $\begin{array}{l}\text { Control centres } \\
n=24\end{array}$ & $\begin{array}{l}\text { Study centres } \\
n=60\end{array}$ & $\begin{array}{l}\text { Control centres } \\
n=105\end{array}$ & \\
\hline $\begin{array}{l}\text { Abortions } \\
\text { Stillbirths } \\
\text { Preterm/premature } \\
\text { Low birth weight } \\
\text { Congenital syphilis }\end{array}$ & $\begin{array}{l}6 \\
4 \\
3 \\
8 \\
2\end{array}$ & $\begin{array}{l}5 \\
2 \\
4 \\
4 \\
1\end{array}$ & $\begin{array}{l}9 \\
1 \\
6 \\
1 \\
0\end{array}$ & $\begin{array}{r}14 \\
9 \\
15 \\
36 \\
2\end{array}$ & $\begin{array}{r}34 \\
16 \\
28 \\
49 \\
5\end{array}$ \\
\hline $\begin{array}{l}\text { Total } \\
\left({ }_{0}^{\circ}\right)\end{array}$ & $\begin{array}{l}23 \\
(56 \cdot 1)\end{array}$ & $\begin{array}{l}16 \\
(66 \cdot 7)\end{array}$ & $\begin{array}{l}17 \\
(28 \cdot 3)^{\star}\end{array}$ & $\begin{array}{l}76 \\
(72 \cdot 4)\end{array}$ & 132 \\
\hline
\end{tabular}

${ }^{\star} \mathrm{p}<0.001$ compared with control centres, post-intervention.

nancy. However, this could be due to difficulty in changing set ideas and beliefs in a short time.

The seroprevalence for syphilis at final phase was $8.0 \%$ (table 2). By comparison, the seroprevalence among prenatal attenders in 1980 and 1983 was $12.5 \%$ and $12.8 \%$, respectively. ${ }^{57}$ This decline in seroprevalence possibly was an effect of the national prenatal syphilis screening programme in its fifth year of implementation and sponsored through UNICEF.

During the pre-penicillin era, the adverse pregnancy outcomes due to maternal syphilis were: $20-40 \%$ abortions, $20-30 \%$ stillbirths, and $25 \%$ born with congenital infection. ${ }^{14}$ However, this study showed lower pregnancy wastages and congenital syphilis (table 5). This could have been due to a number of factors: (1) a prenatal syphilis screening programme which has been underway in Zambia

\section{Table 7 Cost-effectiveness of intervention}

The estimated costs per 1000 attenders would be:

Two tests per attender (an initial visit and a repeated visit in last trimester) at $\$ 0 \cdot 10$ per test

Treatment of all reactors at first visit at $\$ 1.00 /$ treatment

Treatment of subsequent visit at $\$ 1.00 /$ treatment assuming $20^{\circ} \circ$ will be retreated

Treatment of spouses at $\$ 1.00 /$ treatment assuming that $67^{\circ}$ of the spouses of the reactors at the first and second visit will be treated

Amortised cost for development and printing of the behavioural and educational material

Amortised cost for microcentrifuges and lamps

$\$ 200.00$

$\$ 100 \cdot 00$

$\$ 20.00$

$\$ 80 \cdot 00$

$\$ 100 \cdot 00$

Total

$\$ 100 \cdot 00$

$\$ 600.00$ over the past 5 years rendering fewer women in the infectious stage; (2) a few women who aborted at home may not have reported to the hospital; and (3) all newborns of seroreactive mothers were treated immediately at birth. Hence, a real estimate of congenital infection could not be made.

The demonstration project confirmed that the adverse pregnancy outcomes due to maternal syphilis were preventable. Subsequent to intervention, the adverse pregnancy outcomes were reduced by twothirds to $28.3 \%$ in comparison with $72.4 \%$ at the control centres. When comparing the adverse outcomes encountered during the pre- and postintervention phases at the study centres, the reduction was one-half (table 6 ). This was despite a number of inadequacies in the implementation of

Table 8 Reproductive outcome model assuming 10\% seroreactivity in 1000 pregnant women

\begin{tabular}{|c|c|c|}
\hline & $\begin{array}{l}\text { Seroreactive } \\
\text { pregnant } \\
\text { women }\end{array}$ & $\begin{array}{l}\text { Non-sero- } \\
\text { reactive } \\
\text { pregnant } \\
\text { women }\end{array}$ \\
\hline Pregnancies & 100 & 900 \\
\hline $\begin{array}{l}\text { Spontaneous abortions in } 2 \text { nd or } \\
\text { early } 3 \text { rd trimester }\end{array}$ & $20\left(20^{\circ}\right)$ & $27\left(3_{o}^{\circ}\right)$ \\
\hline $\begin{array}{l}\text { Excess spontaneous abortions due } \\
\text { to syphilis }\end{array}$ & 17 & - \\
\hline $\begin{array}{l}\text { Pregnancies extending beyond } 27 \\
\text { weeks }\end{array}$ & 80 & 873 \\
\hline Perinatal deaths & $24\left(30^{\circ}{ }_{0}\right)$ & $52(6 \%)$ \\
\hline $\begin{array}{l}\text { Excess perinatal deaths due to } \\
\text { syphilis }\end{array}$ & 19 & - \\
\hline Syphilitic infants & $14\left(25^{\circ} \%\right)$ & 一 \\
\hline
\end{tabular}


intervention: (1) less than $60 \%$ of women from the study centres had syphilis screening at first attendance and another $15 \%$ had second screening test in the third trimester. This could be explained on the basis that the prenatal clinic attenders are a dynamic population entering the care at different times; (2) less than $50 \%$ of seroreactive women were treated. Although efforts were made to follow up seroreactive women and their partners, a good number of them did not turn up for treatment.

The intervention outlined above is culturally and politically acceptable in Zambia. This programme is relatively inexpensive considering that the cost of intervention for 1,000 pregnant women will be US $\$ 600$ (table 7). If the intervention were perfectly effective, it would prevent 17 spontaneous abortions, 19 perinatal deaths, and 14 syphilitic infants for every 1,000 pregnant women (table 8 ). Thus, the cost of averting each adverse outcome will be US\$12. However, the effectiveness of this programme will depend upon the pattern of attendance at the prenatal clinics, sensitivity of the screening test and treatment of seroreactive women and their spouses. Whatever the limitations, there is urgent need to revitalise syphilis intervention programmes in pregnancy in many developing countries.

This study was funded by the International Development Research Centre, Ottawa, Canada.

Address for correspondence: Dr S K Hira, STD Control Programme, Dermato-Venereology Divi- sion, University Teaching Hospital, PO Box 50001, Lusaka, Zambia.

1 Treponemal Infections. Geneva: World Health Organisation, 1982. pp 44-46. World Health Organisation technical report series; no 674 .

2 Lomholt G. Venereal problems in a developing country. Trop Doct 1976;6:7.

3 Friedman PS, Wright DJM. Observations on syphilis in Addis Ababa. II. Prevalence and natural history. Br J Venereal Dis 1977;53:276-80.

4 Ursi JP, Dyck van E, Houtte van C, Piot P, Colaert J, Meheus A. Syphilis in Swaziland: a serological survey. Br J Venereal Dis 1981;57:95-9.

5 Ratnam AV, Din SN, Hira SK, et al. Syphilis in pregnant women in Zambia. Br J Venereal Dis 1982;58:355-8.

6 Hira SK, Bhat GJ, Patel JB, et al. Early congenital syphilis: clinico-radiologic features in 202 patients. Sex Transm Dis 1985;12:177-83.

7 Hira SK, Bhat GJ, Nyaywa SL, et al. Maternal and congenital syphilis: some epidemiologic aspects. African J Sex Transm Dis 1987;3:3-6.

8 Hira SK, Ratnam AV, Sehgal DB, Bhat GJ, Chintu C, Mulenga RC. Congenital syphilis in Lusaka-I. Incidence in a general nursery ward. East Afr Med J 1982;59:241-4.

9 Hira SK, Ratnam AV, Bhat GJ, Chintu C, Mulenga RC. Congenital syphilis in Lusaka-II. Potential risk and incidence at birth among hospital delivered infants. East $A$ fr Med J 1982;59:306-8.

10 Bhat GJ, Hira SK, Ratnam AV, Chintu C, Mulenga RC. Congenital syphilis in Lusaka-III. Incidence in neonatal intensive care unit. East Afr Med J 1982;59:355-8.

11 Watts TE, Larsen SA, Brown ST. A case-control study of stillbirths at a teaching hospital in Zambia, 1979-80: serologic investigations for selected infectious agents. Bull $W H O$ 1984;62:803-8.

12 US Public Health Service, 1981. STD Fact Sheet No 35, HHS Publication No (CDC) 81-8195.

13 Department of Health and Social Security. Statistical Bulletin, 1988. New cases seen at NHS genito-urinary medicine clinics in England (1976-1986).

14 Dipple $A L$. The relationship of congenital syphilis to abortion and miscarriage, and the mechanisms of intrauterine protection. Am J Obstet Gynecol 1944;47:369-79.

Accepted 1 February 1990 